
\title{
ROLE OF MULTIPARITY IN BIRTH DEFECTS.
}

1. FCPS Part II Trainee Medicine Department, Services Hospital Jail Road, Lahore.

2. MBBS, M.Phil. (Histopathology) Assistant Professor Pathology Department, Azra Naheed Medical College, Lahore.

3. MBBS, M.Phil.

Assistant Professor Pathology Department, Independent Medical College, Faisalabad.

\section{Correspondence Address:} Dr. Muhammad Rafique Cheema Pathology Department, Independent Medical College, Faisalabad.

mrcheema1957@gmail.com

Article received on: 08/05/2017

Accepted for publication: 03/08/2017 Received after proof reading: $08 / 08 / 2017$

\begin{abstract}
Shahbano Jawad', Ikram UI Haq ${ }^{2}$, Muhammad Rafique Cheema ${ }^{3}$
ABSTRACT... Objectives: To study role of parity in the occurrence of congenital malformations in neonates delivered at various hospitals in Lahore. Study Design: Descriptive cross sectional study design was used. Setting: Muhammad Akram Teaching and Research Hospital, Social Security Hospital Manga Mandi and Maternity Center at Raiwind Road, Lahore. Period: Three months, Jan to March 2017. Materials and Methodology: Mothers of 100 malformed neonates were taken as sample. A questionnaire data collection tool was developed and the mothers were interviewed about their age, total number of children, and any history of abortion, miscarriages and complications in pregnancy. Questionnaire was pretested before the data collection. Statistical package for social sciences (SPSS) version 20 was used for entry, compilation and analysis of data. Results: Out of 100 subjects, 76 mothers were multiparous and 24 were primiparous. Out of these $76(100 \%)$ multiparous mothers, $45(59 \%)$ were above 30 years of age, $21(28 \%)$ were between 18 and 30years while $10(13 \%)$ were below 18.The neonates of these 76 mothers were assessed for the type of anomaly having $28(37 \%)$ GIT anomalies, while those with CVS, musculoskeletal, urogenital and facial defects were $15(20 \%), 9(12 \%), 18(23 \%)$ and $6(8 \%)$ respectively. Conclusion: This study suggests that multiparty has an important role in the development of congenital malformations. The number of Urogenital, GIT and CVS anomalies was significantly higher than Facial and Neural Tube defects.
\end{abstract}

Key words: Congenital Malformations, Grand Multiparous. Malpresentation, Macrosomia.

Article Citation: Jawad S, Ikram UI Haq, Cheema MR. Role of multiparity in birth defects. Professional Med J 2017;24(8):1241-1244. DOI: 10.17957/TPMJ/17.4026

\section{INTRODUCTION}

Congenital anomalies are defects at birth. These can be functional, physical or metabolic defects. An estimated 303000 newborns die within 4 weeks of birth every year, worldwide, due to congenital anomalies. ${ }^{1}$ The affected children have a low survival rate and need frequent hospitalizations. Unfortunately they are a continuous source of mental stress and a socioeconomic burden on families. Multiple factors contribute to these defects such as multiparty, increased maternal age, cousin marriages, exposure to the radiations, maternal infections (TORCH), smoking, diabetes mellitus, hypertension, malnutrition and use of drugs. $^{2}$ Out of these, multiparty shares a major contribution in the occurrence of these congenital disorders.

Multiparty is birth to more than one child and grand multiparty is having more than 5 offspring. In developing countries incidence of multiparty is between $30-40 \%$ while in developed countries is becoming low i.e. $3-4 \% .^{3}$ The incidence of malpresentation at the time of delivery, maternal obesity, anemia, preterm delivery, and meconiumstained amniotic fluid increased with higher parity. ${ }^{4}$ The frequency of hypertension, diabetes mellitus, placental complications, operative interventions at delivery, macrosomic infants, chromosomal abbreviations and fetal/neonatal anomalies increased with increasing birth order, being at a maximum in grand multiparas. ${ }^{5}$ Our study was aimed at finding the association of multiparty with congenital abnormalities.

\section{OBJECTIVE}

To study the role of multiparity in the development of congenital anomalies in neonates. Congenital malformations in newborns delivered at various hospitals of public sector in Lahore. 


\section{MATERIALS AND METHODS}

Descriptive cross sectional study design was used. The study was conducted at various clinical set-ups at Lahore. Mothers of 100 malformed neonates were taken as sample. For data collection a questionnaire was developed and the mothers were interviewed about their age, total number of children, any previous malformed children and history of abortion, miscarriages, and complications in pregnancy. A data collection tool (a questionnaire) was developed in keeping with study objectives, dependent and independent variables. Questionnaire was pretested before the data. SPSS computer software was used for entry, compilations and analysis of data. Mothers of malformed neonates were included in the study. However unwilling mothers and those who were too sick to be interviewed were excluded.

\section{RESULTS}

Distribution of parity in mothers of malformed neonates.

Among the 100 mothers studied for malformed neonates, 76 (76\%) were multiparous and 24 (24\%) were primiparous, as shown in Table-I.

\begin{tabular}{|l|c|}
\hline $\begin{array}{c}\text { State of parity in mothers of } \\
\text { Malformed neonates }\end{array}$ & No of mothers \\
\hline Multiparous & 76 \\
\hline Primiparous & 24 \\
\hline Table-I. Distribution of parity in mothers of malformed \\
neonates
\end{tabular}

Systems affected in Children of 76 Multiparous Among the 76 malformed neonates of multiparous mothers studied, the frequency of systems affected is shown in Table-II and Figure-1.

\begin{tabular}{|l|c|c|}
\hline $\begin{array}{c}\text { Systems } \\
\text { affected }\end{array}$ & $\begin{array}{c}\text { No of neonates } \\
\text { with affected } \\
\text { systems }\end{array}$ & $\begin{array}{c}\text { Percentage of } \\
\text { neonates with } \\
\text { affected systems }\end{array}$ \\
\hline GIT & 28 & $36.84 \%$ \\
\hline Urogenetal & 18 & $23.7 \%$ \\
\hline Musculoskeletal & 9 & $11.84 \%$ \\
\hline CVS & 15 & $19.74 \%$ \\
\hline Facial & 6 & $7.9 \%$ \\
\hline \multicolumn{2}{|c|}{ Table-II. Systems affected in children of 76} \\
& multiparous mothers. \\
\hline
\end{tabular}
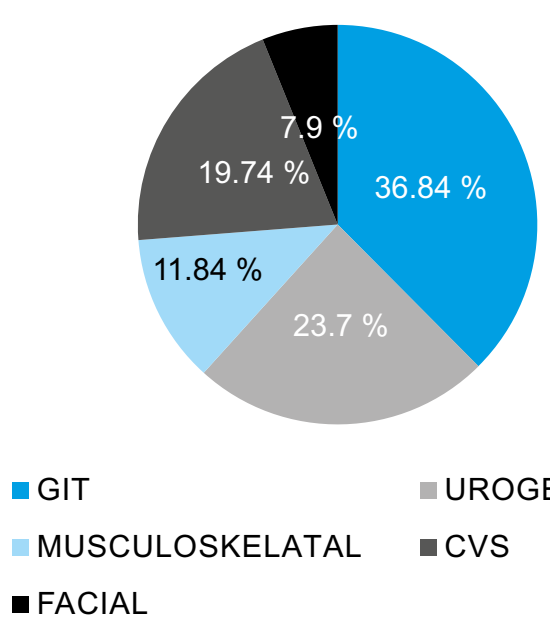

Figure-1. Percentage of systems affected in children of 76 multiparous mothers.

Age distribution of multiparous women studied Among the 76 multiparous mothers studied, 45 $(59.2 \%)$ mothers were above 30 years of age, $21(27.63 \%)$ mothers were between the age of 18 to 30 years, and 10 (13.16\%) mothers were below 18 years of age, as shown in Table-III.

\begin{tabular}{|c|c|c|}
\hline $\begin{array}{c}\text { Age of multiparous } \\
\text { women }\end{array}$ & $\begin{array}{c}\text { No of } \\
\text { mothers }\end{array}$ & $\begin{array}{c}\text { Percentage of } \\
\text { mothers }\end{array}$ \\
\hline Less than 18 years & 10 & $13.16 \%$ \\
\hline $\begin{array}{l}\text { Between } 18 \text { and } 30 \\
\text { years }\end{array}$ & 21 & $27.63 \%$ \\
\hline Above 30 years, & 45 & $59.2 \%$ \\
\hline
\end{tabular}

\section{DISCUSSION}

In our research incidence of congenital malformations was higher in multiparous women as compared to primiparous. This is in correlation with the research carried out by Mir NA, Galczek WC, Soni A on "Easily identifiable congenital malformations in children" which stated that the congenital anomalies were present in $2.38 \%$ of all infants; major and minor malformations were present in $79 \%$ and $21 \%$ of the cases, respectively. Anomalies in general and chromosomal anomalies in particular were more common in multiparous women of advanced age. $^{6}$ Our results showed that the major organ systems involved were gastrointestinal, urogenital and cardiovascular. However above mentioned study showed that "anatomical organs most frequently affected were musculoskeletal and 
cardiovascular systems". Furthermore another study revealed that as compared to primiparous mothers, multiparas mothers had a significantly increased risk of omphalocele, with an OR of 1.59. ${ }^{7}$

The known antipartum complications in the grand multiparas are increased risk of miscarriage, anemia, multiple pregnancy, malpresentation, antipartum hemorrhage and preterm labor. In addition to these, medical complications such as diabetes mellitus and hypertension are seen to complicate these pregnancies more than those of lower parity because of increasing age, poor nutritional status and low socioeconomic conditions leading to birth of malformed babies. This is in concordance with another study in which The incidence of postpartum hemorrhage, preeclampsia, placenta previa, macrosomia, post-date pregnancy, and low Apgar scores were significantly higher in grand multiparas than in multiparas, whereas the proportion of induction, forceps delivery, and total labor complications was significantly lower than in the multiparous group." However another study conducted on outcomes of pregnancy in primiparous versus multiparous women showed that IUGR, uteroplacental insufficiency, preterm labor, oligohydroamnios that could lead to anomalous babies were higher in primiparous. This outcome was explained on the basis that primiparous were mostly un-booked with poor antenatal care in contrast to multiparas who were booked and took good antenatal care. ${ }^{9}$

The results of our study are similar to that carried out in INDIA on congenital anomalies in neonates i.e. the congenital anomalies were more common in multiparas and type of most common defects were musculoskeletal in origin. However in contrast to our study most of the women with malformed neonates were 21 to 30 years of age. This difference in age groups may be associated to the difference in sample collected and also age itself is an independent risk factor for causing malformations with few anomalies' more common in young age while others like Down's Syndrome is more common in old age. ${ }^{10}$
Moreover, according to our research, women aged more than 30 years who were multiparous, have more abnormal babies. This goes in concordance with the research done by Tomatir et al in 2008 with the topic of "Pregnancy Outcome of Multiparas Woman Aged over 40 Years in TURKEY" in which it was found that less than one tenth of the mothers were adolescent and less than one tenth were old mothers. The neonates of older mothers showed a higher incidence of still birth (5.1\% versus $0 \%)$, admission to the neonatal ICU (5.1\% versus $1.03 \%)$ and fetal malformations $(3.09 \%$ versus $0.8 \%)$ than younger mothers. ${ }^{11}$

\section{CONCLUSION}

This study suggests that multiparty has a vital role either direct or indirect in the development of congenital malformations. The number of urogenital, GIT and CVS anomalies was significantly higher than facial and neural tube defects. Also the multiparous mothers over the age of 30 had higher incidence of giving birth to malformed babies. This incidence is higher because of greater ratio of high risk pregnancies, difficult labor and maternal complications in multiparous women. Therefore special antenatal care should be observed for multiparas and proper monitoring should be done along with precautionary measures while delivering neonates of these women. These include prophylactic Iron and folate supplementation, checking fetal presentation at and after 36 weeks and planning mode of delivery. Also identification and good vigilance should be observed for high risk multiparas such as diabetics, hypertensive and women with multiple pregnancies etc. ${ }^{12}$ The risk of development of malformations can also be prevented by proper counseling of primiparas about adoption of good contraceptive measures and prevent grand multiparity that could lead to poor fetal outcomes. ${ }^{13}$

The duration of study was short and sample size was small. It was conducted only in few hospitals so further study might be needed for the implication on general population.

Copyright(c) 03 Aug, 2017. 


\section{REFERENCES}

1. WHO. Congenital anomalies. Fact sheet Updated September, 2016.

2. Birth defects and congenital anomalies. Symptoms \& Causes (Boston Children Hospital).

3. Green F, Devine $O$ et al. Association of paternal age and risk for major congenital anomalies from the national birth defects prevention study, 1997 to 2004. Ann Epidemiol 2010 Mar: 20(3):241-9.

4. Borton C and Tidy C. Gravidity and Parity Definitions (and their Implications in Risk Assessment). Document ID 1324(26).

5. Babinszki A, Kerenyi T, Torok O et al. Perinatal outcome in grand and great-grand multiparity: Effects of parity on obstetric risk factors. Am J Obstet Gynaecol September, 1999; 181(3):669-74.

6. Juntunen K, Kirkinen P. \& Kauppila A. The clinical outcome in pregnancies of grand- grand multiparous women. Acta Obstetricia et Gynecologica Scandinavica 76(8), 1997.

7. Mir NA, Galczek WC, Soni A. Easily identifiable congenital malformations in children: Survey of incidence and pattern in $\mathbf{3 2 , 3 3 2}$ live born neonates. Annals of Saudi Medicine July 1992, 4:366-71.

8. Duong H, Hoyt A, Case A, Walker D. Maternal parity, an independent risk factor. Clinical and Molecular Tetratology, February 2012, 94(4):230-36.

9. Kaur $J$ and Kaur K. Obstetric complications: primiparity Vs. multiparty. European Journal of Experimental Biology 2012, 2(5): 1462-68.

10. Sarkar S, Patra C, Dasgupta M, Nayek K, Karmakar P. Prevalence of congenital anomalies in neonates and associated risk factors in a tertiary care hospital in eastern India. Journal of Clinical Neonatology 2013, 2(3): 131-34.

11. Ates $S$, Batmaz $G$ et al. Pregnancy outcome of multiparous women aged over $\mathbf{4 0}$ years. International Journal of Reproductive Medicine 2013:4.

12. Al-Nahi Q, Dale J, Brown E and Anderson J. Antenatal care in high-risk pregnancies. JRSM Journal of Royal Society of Medicine, 1984; 77(1): 26-32.

13. Simpson J, Fetal outcome among pregnancies in natural family planning acceptors: An international cohort study. American Journal of Obstetrics and Gynecology. December 1991, 165(6):1981-82.

\section{AUTHORSHIP AND CONTRIBUTION DECLARATION}

\begin{tabular}{|c|l|l|l|}
\hline Sr. \# & \multicolumn{1}{|c|}{ Author-s Full Name } & \multicolumn{1}{|c|}{ Contribution to the paper } & Author=s Signature \\
\hline 1 & Shahbano Jawad & Questienaires \& Data \\
\hline 2 & Ikram UI Haq & Paper Writing \\
\hline 3 & Muhammad Rafique Cheema & Tables \& Graphs \\
\hline
\end{tabular}

